\title{
Dialética e práxis no pensamento de Jean- Paul Sartre (Uma leitura da Crítica da razão dialética)
}

Arno Münster

Université de Picardie-Jules Vernes / Amiens

resumo 0 artigo mostra a conversão teórica sartriana na direção do materialismo histórico e do marxismo. Destaca que essa conversão jamais implicou o abando no de certos conceitos do existencialismo. Na Crítica da razão dialética, Sartre buscou definir uma nova dialética, em que a dimensão existencial e subjetiva é parte do processo de transformação econômica, política e social.

palavras-chave Sartre; dialética; marxismo; existencialismo; práxis.

A gênese do "fenômeno" Sartre é sem dúvida ligada à emergência, em um contexto histórico determinado, de um pensamento forte, crítico, original e radical, adaptado a se desenvolver e se metamorfosear constantemente em condições filosóficas, históricas e políticas mutáveis que, indubitavelmente, influenciaram e marcaram este pensamento sem, todavia, atingir suas estruturas fundamentais e sua escritura filosófica. Se o"existencialismo" sartriano reenvia diretamente a sua apropriação da fenomenologia husserliana nos anos 30 do vigésimo século, forçoso é constatar que esta herança fenomenológica se concretiza nos escritos filosóficos de Sartre do seu primeiro período sob a forma de uma aprendizagem crítica e constestatória da fenomenologia, em que a intenção declarada de Husserl de "se dirigir diretamente às coisas mesmas" através da redução eidética, será simultaneamente transformada e reconduzida sob a forma da "pesquisa, da busca de uma filosofia claramente orientada para as existências concretas e dadas". Como sublinhou justamente Jean- 


\section{4}

Marc Mouillie, "o descobrimento da fenomenologia não impede que se faça sentir a pressão da história nem que se exprima o cuidado com o outro. Parece traduzir a intenção primeira de Sartre para o acontecimento e a contingência" (MOUILLIE, 2000, p. 13).

E ainda que Sartre conduza efetivamente a fenomenologia no caminho da ontologia, em $O$ ser e o nada, e, depois do descobrimento da ontologia de Heidegger, esta mesma vontade de ultrapassar e de se apropriar ao mesmo tempo da ontologia fenomenológica, levou Sartre inevitavelmente ao esboço das linhas gerais de uma ontologia fenomenológica existencial que comporta também já certas críticas a Heidegger, por exemplo: (1) a crítica do conceito heideggeriano de angústia (Angst) na analítica ontológica existencial; e (2) uma crítica do conceito heideggeriano de Mit-Sein (ser-com), conceito que não é aplicado por Sartre à comunidade nem à famosa "comunidade do povo" de Heidegger, mas exclusivamente à relação do Ego ao Outro.

E esta dissidência com respeito a Husserl e Heidegger permitiu a Sartre esboçar e desenvolver nos anos 40 a sua própria filosofia do Ser, do Nada e da Existência, que enriqueceu de maneira considerável a história da filosofia contemporânea através de um número importante de conceitos novos, como por exemplo o conceito de serialidade, de exis, de prático-inerte e de contra-finalidade.

Em etapas sucessivas, este pensamento ontológico-fenomenológicoexistencial aproximou-se do materialismo histórico e do marxismo. E se Sart re realizou esta viragem teórica importante para o que agora lhe parece "incontornável", quer dizer, o marxismo, apenas dezessete anos depois da publicação de O ser e o nada, isso é incontestavelmente devido à existência de fortes resistências do filósofo francês contra o materialismo e contra todo pensamento baseado em um determinismo objetivo da matéria econômica e social, de maneira que isso impediu efetivamente toda conve rsão de Sartre a uma filosofia materialista que nega a prevalência absoluta da existência sobre a essência. A conseqüência disso é que Sartre, apesar de sua conversão ao marxismo nos anos 50, não quis jamais abandonar completamente certos conceitos e teoremas do existencialismo. Convertido em "marxista", ele tornou-se rapidamente - exceção feita dos seus quatro anos de "compagnon de route" dos comunistas, entre 1952 e 1956 - um marxista dissidente, abandonando rapidamente os 
dogmas de um marxismo ossificado e stalinista, desafiando abertamente a ortodoxia marxista-leninista-stalinista e tentando definir uma nova dialética, escapando aos cânones oficiais do marxismo soviético, quer dizer, uma dialética renovada e vivente tomando em conta não só as determinações econômicas e sociais objetivas da sociedade burguesa-capitalista, mas também as subjetividades constituídas e constituintes implicadas nos processos de transformação revolucionária da história.

E esta vontade de salva gua rda absoluta do fator subjetivo-existencial para um materialismo histórico e dialético renovado caracteriza o resultado específico desta conversão de Sartre ao marxismo, quer dizer, ao existencialo-marxismo da Crítica da razão dialética, que não é redutível a um existencialismo marxista - como sugere, entre outros, Thomas Flynn (FLYNN 1985) -, mas ao esforço sartriano de enriquecer o materialismo histórico pela entrada da dimensão existencial e subjetiva dos indivíduos e grupos no processo de transformação econômica, política e social.

Como o sublinha entre outros Hadi Rizk, a Crítica da razão dialética de Sartre tem como ponto de partida a necessidade de dar conta apenas pela práxis individual da gênese do coletivo.

A materialidade do ato de viver determina-se - através da superação da raridade - como uma "negação da negação" no sentido da impossibilidade da impossibilidade de viver (existir). O organismo individual é muito menos uma perseverança no ser do que uma existência problemática atravessada pela raridade. Ele não tem um ser, mas deve sem cessar alcançar (obter) o seu ser. A raridade desenha um acontecimento ontológico primeiro quer dizer, uma impossibilidade de coexistir - e, simultaneamente, uma impossibilidade vivida e reapropriada pelos indivíduos para se libertarem que transforma a relação recíproca e a co-pertinência inscrita na relação humana em uma reciprocidade do antagonismo" (RIZK 1996, p. 11).

O nosso primeiro objetivo é esboçar em primeiro lugar a gênese deste conceito de práxis no pensamento de Sartre e sua evolução de um conceito definido - na primeira filosofia ontológico-fenomenológica exclusivamente como atividade/ação individual, na esfera da realização das possibilidades redutíveis à ação da consciência intencional de um indivíduo, para um conceito de práxis de um coletivo, quer dizer, de um grupo-em-fusão que ultrapassa a serialização, constituindo-se pela ação para atingir tal objetivo. 


\section{6}

Isso implica necessariamente a análise do processo de gênese da unidade de um grupo em fusão que se atesta na ação comum, rebelandose contra uma realidade vivida como impossibilidade de viver. Trata-se em conseqüência de analisar a função da práxis no quadro de uma ontologia histórica do social tal como é esboçada por Sartre na Crítica da razão dialética. Esta ontologia social não define, di ife rentemente daquela proposta por Marx e Lukács, a realidade social, a sociedade como uma totalidade ou entidade estável fundamentada sobre estruturas econômico-sociais objetivas, atravessadas por contradições, mas como um "serúnico da multiplicidade inter-individual" e como uma "necessidade nãoultrapassável de um ser-em-comum da impotência” (RIZK 1996, p. 12).

Vê-se que em relação aos conceitos de "raridade", "necessidade" (besoin), "alienação" e também "trabalho", quer dizer em relação a estes conceitos "clássicos" do marxismo, Sartre procede voluntariamente desde o início a uma ontologização do vocabulário de Marx, que é às vezes um pouco "excessiva", mas que é a conseqüência de suas raízes filosóficas na fenomenologia. Isso é particularmente pertinente quando Sartre define, por exemplo, a raridade como um evento ontológico de primeira importância; ou quando define a sociedade quase exclusivamente através do paradigma da intersubjetividade e das reciprocidades inter-individuais, em detrimento da análise sócio-materialista que todavia não é ausente em sua análise. E com respeito à definição dos conceitos de trabalho e alienação, Sartre está privilegiando mais uma vez o aspecto ontológico em detrimento do aspecto de determinação objetiva (materialista).

Isto nos convida automaticamente a analisar rigorosamente a relação de Sart re a Marx, uma relação complexa e não redutível a uma simples conversão (sem reservas) de Sartre ao materialismo histórico e dialético. Para caracterizar a ve rdadeira natureza desta relação, poder-se-ia - ao voltar ao século XIX, e aqui me inspiro em uma frase pronunciada em 16 de abril de 2005 por Sylviane Agacinski, por ocasião de uma homenagem a Sart re organizada pela Biblioteca Nacional de Paris - comparar a relação filosófica de Kierkegaard a Hegel. Trata-se evidentemente do desafio lançado em nome de uma subjetividade singularizada da existência contra o pensamento de um sistema fechado onde tudo obedece a uma racionalidade universal - totalizadora - do espírito objetivo. Em conseqüência, não é errado pretender que a relação de Sartre a Marx se 
situa exatamente no mesmo nível, quer dizer, corresponde exatamente à relação crítica do filosofo dinamarquês a Hegel. É significativo que Sartre, mesmo quando rende homenagem a Marx, por exemplo, nas páginas dedicadas a Marx no livro Les communistes et la paix (Os comunistas e a Paz) (1952) ou na Crítica da razão dialética (1960) (onde Sartre evoca e cita freqüentemente a Ideologia alemã e o Capital de Marx), Sartre não cessa de sublinhar (Cf. Questões de método, o ensaio introdutório à Crítica da razão dialética) que a sua adesão ao marxismo, “o pensamento incontornável de nossa época", não equivale de nenhuma maneira a uma renúncia ou uma revogação do seu existencialismo. O que Sartre visa é a síntese do existencialismo e do materialismo histórico e dialético, síntese que lhe permite manter certos conceitos da fenomenologia pela tentativa de esboçar uma ontologia social (materialista) ampliada por uma antropologia histórico-social. O que interessa a Sartre principalmente - e isso é também confirmado pela entrevista de Sart re a Michel Contat no ano de 1975, publicada pelo semanário francês "Le Nouvel Observateur" - é a mistura das duas filosofias (materialista e existencialista) e a salvação máxima da preferência subjetiva (existencial) no quadro de uma filosofia existencialomarxista que admite só com certas reservas a tese de Marx de que a consciência dos indivíduos e classes sociais seja em última instância determinada pelos fatores objetivos da produção e da economia capitalistaburguesa e pelos valores da sua superestrutura. Esta vontade de salvaguardar o fator subjetivo - dentro de uma visão do mundo materialista, mas aberta e des-dogmatizada - poderia permitir em princípio uma aproximação dos pontos de vista filosóficos do Sartre da Crítica da razão dialética com as posições da Escola de Frankfurt; porque a salvagua rda do momento "particular" e dos "direitos imprescritíveis do individuo" (ADORNO, 1966) ${ }^{1}$ (com seus sofrimentos) em uma filosofia materialista foi também o objetivo declarado da Dialética Negativa de Adorno. Tratase todavia de uma convergência parcial e circunstancial que não pode apagar o desacordo fundamental da Escola de Frankfurt com os vários representantes do existencialismo francês (incluindo Sartre), criticados e condenados - também por Lukács e Ernst Bloch - por "subjetivismo" excessivo e por suas raízes na ontologia fenomenológica de Heidegger.

Quando Adorno publicou o seu artigo "Dialética e Engajamento", não havia ainda lido a Crítica da razão dialética de Sartre, e Sart re do seu 
lado não havia lido nem a Dialética do Esclarecimento de Horkheimer/ Adorno nem os outros livros dos autores da Escola de Frankfurt. Sart re ignorou também os escritos do filósofo alemão Ernst Bloch, apesar de numerosas convergências políticas com Sartre depois da sua ruptura com o regime stalinista da República Democrática Alemã em 1956. Evidentemente, a polêmica de Adorno contra Heidegger conduzia o maior filósofo da Escola de Frankfurt a olhar para O ser e o nada de Sartre (subtítulo: "Ensaio de ontologia fenomenológica") com muita desconfiança, sem tomar realmente em conta as diferenças que separam Sartre e Heidegger, por exemplo: o dualismo ontológico de Sartre e sobretudo a vontade explícita de Sartre de deslocar a pesquisa filosófica da ontologia (no sentido que a compreende Heidegger) para a antropologia. (Assim, a Crítica da razão dialética persegue o objetivo de uma dedução dialética das categorias histórico-sociais a partir das estruturas antropológicas fundamentais que foram já elaboradas no Ser e o Nada. Entre elas figuram as estruturas do valor e do projeto que estão diferenciadas por Sart re (a) em um conceito estrutural abstrato do valor e (b) em uma entidade concreta e social do valor (SEEL, 1995, p. 22)).

O primeiro grande objetivo da Crítica da razão dialética é fornecer a prova da existência da razão dialética, quer dizer, de uma racionalidade dialética na História. Uma vez esta prova fornecida, o dualismo entre Ser e Verdade pode ser ultrapassado. Admitida a existência desta razão dialética, ela não pode ser outra coisa que uma racionalidade constituindo-se, efetuando-se sempre na relação dialética entre indivíduos, grupos e "grupos-em-fusão" com a materialidade circundante, quer dizer, com o prático-inerte. É nesta perspectiva que Sart re analisa agora a práxis dos indivíduos, grupos e classes sociais na história, sempre tomando em conta as contra-finalidades da práxis causadas pelos efeitos de reificação e alienação produzidos pela matéria trabalhada do prático-inerte. Como foi sublinhado, entre outros, por Leo Fretz (FRETZ, 1988, p. 247 ss), na sua contri buição ao Congresso Sartre Internacional de Frankfurt, o segundo objetivo da Crítica da razão dialética foi a descrição do fundamento antropológico do fenômeno da alienação. Esta descrição efetua-se no pensamento de Sartre em uma perspectiva claramente ontológica, baseada na convicção de que o fundamento de uma teoria histórico-materialista da História não pode ser senão uma antropologia ontológica estrutural 
tornando inteligível a práxis no processo histórico, p o rque as relações inter-humanas se exprimem sempre em formas alienadas. Sartre acha efetivamente que é inevitável tentar determinar as condições de possibilidade do fenômeno da alienação. Por um lado, a prova irrefutável da existência da razão dialética exige uma evidência apodítica e isso implica que o conhecimento e o Ser sejam materialmente dados em um só e único ato. De outro lado, a determinação das condições transcendentais do fenômeno da alienação na história pressupõe a análise antropológica dos elementos característicos da história humana. Assim, a análise de Sartre é simultaneamente histórica e transcendental. Em conseqüência, o objetivo da Crítica da razão dialética é duplo: (a) compreender - de um lado - a necessidade da razão dialética, a partir da experiência histórica, e (b) de outro lado, evidenciar a necessidade da História como processo de alienação da práxis dos indivíduos, grupos e classes sociais. Isso determina a estrutura das quatro seções do Livro I da Crítica da razão dialética: $1^{\circ}$ Sart re esforça-se em provar a evidência do Cogito dialético; $2^{\circ}$ tenta evidenciar a apoditicidade desta evidência e da existência irrefutável do outro; $3^{\circ}$ Sartre procura determinar as condições estruturais antropológicas do fenômeno hegeliano-marxista da alienação e $4^{\circ}$ esforça-se em determinar a estrutura fundamental da serialidade como alienação primeira e evidenciar a contra-finalidade como forma alienada da práxis humana na história (FRETZ, 1988, p. 249).

Devemos evidenciar também que esta nova concepção da dialética de Sart re articula-se com a renovação e reatualização do conceito de práxis que não é simplesmente uma reformulação do conceito de práxis de Marx ou de Gramsci, mas a fundação de um novo conceito de práxis no campo de tensão permanente entre o existencialismo, o marxismo, a história e a antropologia. É evidente que na Crítica da razão dialética (1960) Sartre já definitivamente ultrapassou a concepção fenomenológica individualista e solipsista (no sentido da "ipseidade" heideggeriana) da práxis do Ser e o Nada, quer dizer, a práxis da consciência intencional do Para-Si, atuando espontaneamente em direção ao mundo, para uma outra visão da práxis que concerne agora prioritariamente a práxis dos grupos, dos "grupos-em-fusão" e das classes sociais. Como foi sublinhado entre outros por Günter Zehm (ZEHM, 1964, p. 187), o elemento novo da Crítica da razão dialética é que a tentativa do Ego de tornar-se tal no 
mundo não se termina mais pela negação ("néantisation") do mundo e que, simultaneamente, a tentativa de se tornar "outro" não se realiza mais pela sujeição do outro pelo Ego (como no Ser e o Nada). Efetivamente, Sartre inteira-se do fato de que as relações humanas não são mais exclusivamente caracterizadas pela "luta de todos contra todos" (Hobbes), mas que existem também outras formas antropológicas significativas positivas, como por exemplo a solidariedade humana. Em O ser e o nada, o meu "ser-para-o-outro" foi ainda definido como queda através de um vazio para a objetividade. Como esta queda é alienação, eu não posso me fazer objeto para mim mesmo (SARTRE, 1943, p. 276).

Como sublinha Zehm, no Ser e o nada o Para-si-objeto era só um motivo de "indisposição para o Ego", e era em conseqüência um "arrancamento da unidade ek-stàtica do Para-Si". Agora, na Crítica da razão dialética, o Outro não é mais necessariamente estrangeiro ao Para-Si; porque a luta comum dos oprimidos contra a exploração ensina ao Para$\mathrm{Si}$ a acreditar no mundo objetivado. Em outras palavras: "Através da luta de classes, o Para-si torna-se um espelho, em lugar da convergência do sentimento de co-pertencimento e de solidariedade. Assim, o Para-Si desdobra-se inteiramente no Outro (por exemplo, no mundo do trabalho). É no nível da solidariedade de grupo que os trabalhadores realizam e consolidam sua existência de maneira que não podem mais cair no Nada" (ZEHM, 1964, p. 188). Essa é a razão por que - no Sartre da Crítica da razão dialética -, a práxis do grupo é sempre a maior condição da possibilidade para a ação e a história. É a prática comum que é constitutiva da fundação da história. $\mathrm{O}$ indivíduo só pode ter acesso à História através dos grupos sociais (os grupos-em-fusão). E a evolução do grupo para a História é a única possibilidade de reintegrar o universo da alienação, porque para Sartre os "resultados da síntese (da práxis e da história) são sempre alienados" (ZEHM, 1964, p. 189). O objetivo da História é a reintegração do mundo da economia (como segunda natureza) na esfera de uma dialética existencial não-alienada. É claro que o sujeito desta transformação é a classe operária como única classe histórica capaz de realizar esta transformação (ZEHM, 1964, p. 189).

Tentei evidenciar como o esforço de Sart re de esboçar neste quadro os fundamentos teóricos para uma nova teoria dos conjuntos práticos o conduzia da análise das formas específicas da práxis individual como 
totalização de um pro-jeto no campo prático a uma análise aprofundada das implicações da práxis no processo histórico de uma nova dialética que, de forma distinta daquela esboçada por Marx e Engels, preconiza que "toda dialética histórica é fundamentada na práxis dos indivíduos enquanto ela já é dialética". Necessariamente, esta teoria sartriana da práxis desenvolve também uma nova teoria dos conflitos e da práxisprocesso no contexto da violência (colonialista) na História contemporânea que constitui o último capitulo da Crítica da razão dialética (SARTRE, 1960, p. 799 ss).

Estas análises sartrianas têm como característica geral a vontade do autor de libertar o materialismo histórico e dialético, quer dizer, o marxismo, das engrenagens de uma dialética sócio-materialista demasiado mecanicista e simplificada, funcionando exclusivamente segundo o esquema das contradições sócio-econômicas definidas segundo os conceitos-chave da crítica marxista da economia política, e de validar, para uma nova ontologia do social e para uma nova teoria neo-marxista(existencialista) da emancipação e da alienação, o papel importante da práxis dos indivíduos e dos grupos. Claro que se pode objetar a esta nova teoria ter negligenciado a verdadeira dialética sujeito-objeto, ter esboçado exclusivamente uma ontologia dos grupos e de oscilar constantemente entre uma teoria da razão dialética e da ação direta (ZEHM, 1964, p. 180). Neste contexto, quero também enfatizar que o conceito de "grupo" - tão freqüentemente utilizado por Sartre em detrimento do conceito de "classe" - não é um conceito marxista (é de preferência "fourierista"), e que para ele a classe (social) não é mais definida como uma entidade sociológica estável, mas como uma força social e moral que nasce a cada vez, espontaneamente, sobre o terreno dos conflitos econômico-sociais na história, mas que se descompõe depois da fase aguda destes conflitos, como, simultaneamente, os grupos-em-fusão, depois ter obtido o seu objetivo, recaem na serialidade. Pelo conceito de grupo e de grupo-em-fusão, Sartre se inspirou evidentemente da experiência que fez pessoalmente quando fundou, em março de 1941, depois de sua libertação do Stalag (do campo de prisoneiros na Alemanha), junto com JeanToussaint, Dominique Desanti e alguns outros amigos politicos, o grupo de Resistência intelectual Socialisme et Liberté (Socialismo e Liberdade), grupo de resistência que foi autodissolvido já em outubro de 1941. 
(Alguns de seus membros entraram depois na Resistência comunista dos F.T.P.) Esta preferência de Sart re pelo conceito não-marxista de grupo e de grupo-em-fusão é uma outra prova da tese de que a apropriação por Sartre da doutrina de Marx acompanha-se desde o início do esforço do filósofo existencialista francês de ultrapassar Marx e a doutrina do materialismo histórico e dialético em uma nova teoria da práxis fundamentada essencialmente sobre a práxis dos indivíduos e dos grupos. Assim, Sartre, depois ter sido durante só quatro anos o "companheiro" dos comunistas, define-se claramente, a partir da sua ruptura com o comunismo soviético, em outubro 1956, depois da sangrenta repressão da insurreição popular na Hungria, como um dissidente face ao stalinismo, mas sua dissidência é uma dissidência diferente daquela dos outros dissidentes do campo do marxismo-leninismo dogmático, na medida em que Sartre, apesar da sua adesão ao materialismo histórico e dialético, nos anos cinqüenta, não quis jamais renunciar ao teorema maior de sua própria filosofia existencialista, a saber, à prevalência do fator individual-subjetivo sobre o fator objetivo e coletivo. Em conseqüência, a sua adesão ao marxismo foi desde o início uma adesão com certas reservas teóricas, exprimindo também a firme resolução de Sartre de limitar a priori as concessões feitas ao marxismo (ortodoxo) no terreno da subjetividade e de continuar, em certos limites, também a desafiar o determinismo objetivo do materialismo histórico.

A diferença que separa sempre Sart re de Marx é também perceptível no nível de um conceito-chave da dialética hegeliano-marxista: o conceito de trabalho. Enquanto o trabalho é definido por Marx simultaneamente como auto-realização do homem e como alienação causada pelo modo de produção capitalista, Sart re define o trabalho de p referência como uma mediação ontológica, como uma relação dialética de exteriorização e de interiorização, no quadro de uma relação de reciproidade mediatizada do homem (trabalhador) com a matéria (transformada). Esta mediação é caracterizada por um duplo processo dialético constituído: $1^{\circ}$ pela ação subjetiva do homem trabalhando sobre a matéria transformada e $2^{\circ}$ pela determinação - de volta - da consciência do homem pela matéria objetiva transformada. O práticoinerte indica a transformação da ação humana sobre a matéria inorgânica em um poder da materia trabalhada sobre a práxis. Esta teoria da dupla dialética corresponde exatamente à vontade sartriana de escapar a 
uma teoria da determinação objetiva absoluta da consciência pela matéria e pelo ser social objetivo. Ao opor o conceito de raridade ao de necessidade e ao definir a raridade não a partir das categorias da crítica da economia política, mas como um evento ontológico produzindo uma impossibilidade de coexistir que transforma a relação recíproa dos homens em uma reciprocidade do antagonismo, Sart re corrigiu (completou), com esta teoria da reciprocidade do antagonismo, a teoria clássica do marxismo da "luta de classes". Ele define assim uma nova dialética onde "a transição da atividade constituinte, quer dizer, da liberdade, para a alienação, tem como condição de possibilidade a mediação da matéria trabalhada" (NOUDELMANN e PHILIPPE, 2004, p. 112). Sobre estas condições, como enfatiza Hadi Rizk, o prático-inerte explica-se como uma equivalência dohomem-coisa e da coisa humana na medida em que a matéria trabalhada é o termo mediador entre a atividade constituinte (da liberdade) e a dominação (RIZK 1996, p. 12). A ação passiva que exe rce a matéria do prático-inerte sobre os homens produz a práxis negativa sobre a forma da contra-finalidade. $\mathrm{O}$ segundo volume da Crítica da razão dialética explica também a genêse da práxis-processo a partir dos desvios da práxis pelas contra-finalidades; ela encarna a superação de cada um destes desvios.

\section{Conclusão}

Situando-se no cruzamento do existencialismo e do materialismo histórico, da sociologia marxista e da antropologia, da história políticosocial e da ontologia social, a Crítica da razão dialética de Sartre inscrevese na história da filosofia contemporânea como uma obra em vários aspectos ve rdadeiramente excepcional. Escrito na euforia de um pensamento que se renova constantemente numa velocidade vertiginosa, entre 1957 e 1959, este livro marca uma cesura importantíssima não só no pensamento do filósofo francês, mas também na história do pensamento dialético crítico-materialista contemporâneo, na medida em que tenta tirar as grandes lições teóricas dos últimos acontecimentos históricos mundiais que afetaram o marxismo durante os anos 50 do vigésimo século, e esboçar ao mesmo tempo os fundamentos teóricos de uma dialética 


\section{4}

renovada, desossificada e completamente liberada das visões dogmáticas do marxismo-leninismo ortodoxo (soviético) que se tornou, na época de Stalin, a ideologia dominante de um sistema extremamente burocrático e totalitário. É também o testemunho da conversão teórica corajosa de um Jean-Paul Sartre que, de 1952 até 1956, foi o "companheiro de estrada" dos comunistas, numa época em que o PCF atravessava ainda os boulevards das cidades francesas com caminhões ornados com retratos de Stalin. Revela também a vontade inabalável do autor do livro "Os comunistas e a paz" (Les communistes et la paix) (1952) de romper com o "comunismo dos tanques", cuja prática "marxista” tornou-se o contrário absoluto da teoria de Marx. Incontestavelmente, os acontecimentos trágicos na Hungria, em outubro-novembro de 1956, foram determinantes para esta virada de Sartre, mas não podemos excluir a hipótese de que as severas críticas pro nunciadas por Merleau-Ponty no liv ro As Aventuras da Dialética (Les aventures de la dialectique) (1955), a propósito do engajamento procomunista de Sartre, a partir do ano 1952, produziram um efeito tardio sobre o pensamento de Sart re incitando-o a reajustar o seu próprio dispositivo teórico. Isto não era fácil, mas Sartre solucionou de forma brilhante este problema, reafirmando-se como filósofo da liberdade. Questions de Méthode (Questoes de método) - um ensaio escrito em 1957 para uma revista polonesa - já anunciava esta volta de Sart re para uma nova dialética definindo-se agora em ruptura total com a dialética marxista-leninista oficial e canonizada. O fato de que Sart re re-publicou este ensaio como capítulo introdutório da Crítica da razão dialética é significativo desta saída definitiva de Sartre do seio da ortodoxia marxista. Assim, Sartre efetuou uma viragem que, em outras circunstâncias, lhe teria cert amente permitido aproximar-se das posições filosóficas da Teoria Crítica de Frankfurt e sobretudo de Adorno que, com a publicação da Dialética Negativa (1966), defendia também a necessidade de uma nova dialética, de uma dialética da "deslocação", do desafio total contra toda positividade e identificação (cripto)-totalitária.O que une Sartre e Adorno - apesar de todas as diferenças filosóficas que os separam - é incontestavelmente este esforço de defender a prevalência do fator subjetivo, individual dentro de uma filosofia social e de uma filosofia da história materialista (mesmo que Adorno a defenda menos radicalmente do que Sartre); é a vontade de libertar o materialismo histórico de uma dialética demasiado mecanicista 
baseada em um determinismo sócio-econômico reclamando-se de uma "visão científica do mundo" que é na verdade reducionista com respeito à visão emancipadora de Marx; é a resolução de opor simultaneamente a esta visão materialista-mecanicista uma filosofia dialética nova, crítica, aberta e perspicaz, evitando a queda no economicismo puro e no determinismo absoluto pela objetividade, incapaz de levar em conta a complexidade das relações sociais e da ação determinante dos indivíduos na história. O que separa todavia Sartre de Adorno é o desinteresse manifesto do fundador da Escola de Frankfurt - quer dizer do último Adorno dos anos 60 - pelo conceito de práxis e pela práxis em geral; é esta fuga do co-fundador (com Max Horkheimer) da Teoria crítica da sociedade na estética, e finalmente também a não-solidariedade política de Adorno, Horkheimer e Habermas com o movimento contestatório dos estudantes de maio 1968, movimento anticapitalista, anti-imperialista, pacifista e anti-autoritário que foi todavia muito inspirado e influenciado, em seus inícios teóricos, pela crítica da sociedade burguesa, da educação e da filosofia da práxis do jovem Horkheimer: não-solidariedade que contrasta efetivamente com a simpatia generosa que Jean-Paul Sart re, falando aos estudantes em rebelião na Sorbonne ocupada, manifestou por este movimento emancipador da juventude. E contrariamente a Adorno, Sart re afirma na Crítica da razão dialética que "a dialética é práxis e que a práxis é dialética sempre como práxis dos indivíduos” (SARTRE, 1960, p. 137). Incontestavelmente, a evolução de Sartre da ontologia fenomenológica ao existencialo-marxismo e ao materialismo histórico tem como conseqüência sua articulação com a antropologia e com uma ontologia social que, evidentemente, apresenta-se como uma ontologia social menos materialista e marxista que a de Georg Lukács, mas que enriquece incontestavelmente a filosofia social contemporânea pelo descobrimento de nume rosas relações de intersubjetividade e de reciprocidade mediatizadas. Lamentando - com Ernst Bloch - o pouco interesse de Sartre pelas utopias, queremos enfatizar ao mesmo tempo que Bloch, Adorno, Marcuse e Sart re poderiam se unir, apesar de todas as diferenças de pontos de vista, no combate comum contra o que Sartre chama o hiperempirismo dialético de Gurvitch, o estruturalismo e o neo-positivismo. Para Sart re, trata-se, sem dúvida, em face da dialética dogmática, hiperempirista e esclerosada do stalinismo, de retomar o problema do início e 
de se perguntar quais são realmente os limites, a validade e a verdadeira extensão da razão dialética. Sart re insiste em conseqüência que não há outra via que "fundamentar e desenvolver esta razão dialética como crítica livre de si mesma e como movimento da História e do conhecimento" (SARTRE, 1960, p. 141). Trata-se de libertá-la do bloqueio do dogmatismo. Segundo Sartre, a origem deste dogmatismo deve ser procurada na dificuldade fundamental do materialismo dialético, que foi libertado do movimento da dialética idealista-hegeliana por Marx. Segundo Sartre, a originalidade de Marx consiste indubitavelmente em evidenciar contra Hegel que a História é sempre em evolução, que o Ser é irredutível ao Saber e que se trata em conseqüência de conservar o movimento dialético simultaneamente no Ser e no Saber. Marx, disse Sartre, "pensa a razão - praticamente. Resta que por falta de ter re-pensado a dialética, os marxistas fizeram o jogo dos positivistas..." (SARTRE, 1960, p. 142). Mas esta crítica não concerne - bem entendido - o neo-marxismo em geral, mas exclusivamente as deformações dogmáticas do marxismo no século XX; não concerne o neo-marxismo de Gramsci, de Adorno, de Bloch, de Marcuse ou de Henri Lefebvre, porque existe um acordo teórico quase total entre Sartre, os fundadores da Escola de Frankfurt e Ernst Bloch unicamente com respeito à exigência de que "o marxismo como dialética deve absolutamente rejeitar o relativismo dos positivistas e que é necessário evidenciar contra o positivismo que a Razão dialética pode hoje enunciar toda a verdade, pelo menos as verdades totalizadoras" (SARTRE, 1960, p. 143). Opondo-se a apoditicidade do conhecimento dialético que - segundo Hegel - implica uma identidade do Ser, do Fazer e do Saber, Sartre reclama-se agora diretamente de Marx, que já havia afirmado contra Hegel que "a existência material é irredutível ao conhecimento" e que "a práxis transborda o Saber de toda sua eficácia real" (SARTRE, 1960, p. 143). Em conseqüência, Sart re pode afirmar que "o pensamento é simultaneamente o Ser e o conhecimento do Ser. E a práxis de um indivíduo ou de um grupo em condições determinadas em um momento definido da História. Como tal, ela suporta a dialética como sua lei, do mesmo modo que o conjunto e o detalhe do processo historico" (SARTRE, 1960, pp. 144-145).

Mas ela é também conhecimento da dialética como razão, quer dizer, como lei do Ser (SARTRE, 1960, p. 143). 
Para resumir, poder-se-ia concluir - com Iring Fetscher - que a principal retificação que Sart re faz ao marxismo consiste na tentativa de completar as leis objetivas exteriores que evoca o marxismo pelas leis interiores [intersubjetivas, antropológicas, existenciais] pelas quais todos os acontecimentos históricos são mediatizados. De outro lado, trata-se também de evidenciar a singularidade dos indivíduos através de seu condicionamento pelo universal, quer dizer, pelas condições sociais desenvolvendo-se historicamente e que são os produtos da ação dos indivíduos. Esta vontade sartriana de aplicar um corretivo à teoria marxista explica-se pela sua convicção de que o materialismo histórico (dogmatizado) não é senão uma versão modificada da sistematicidade hegeliana onde o indivíduo singular desaparece, ou seja, é simplesmente reduzido a um agente do espírito mundial (FETSCHER, 1988, p. 229).

Não obstante, deveríamos absolutamente considerar como séria a renovação da dialética marxista inaugurada por Sartre pela validação do fator subjetivo e pela superação do dogmatismo marxista estéril (FETSCHER, 1988, p. 243).

Para concluir, quero só lembrar o que disse Iring Fetscher ao termo de sua conferência intitulada "Sartre e o marxismo", pro nunciada no Congresso Sartre Internacional organizado na cidade de Frankfurt, em 1987, 10 anos depois da publicação da Crítica da razão dialética em alemão:

"Raymond Aron havia definido Sartre como 'um moralista desvairado na politica'. Nós pensamos que Aron não tem razão de brincar assim com a diferença entre a filosofia moralista, de um lado, e a política profissionalizada, de outro. Porque, como Sartre enfatizou em seu ensaio sobre o 'Maio 68 e suas conseqüências', 'nós nascemos todos como seres políticos na cidade, façamos ou não política. Não existe uma vida individual ou familiar que não seja condicionada pelo conjunto social do qual fazemos parte. E essa é a razão pela qual cada um de nós deve agir sobre os grupos que nos determinam, que seja (ou não) empurrado pelo curso das coisas ou que tente dar-lhes uma direção. Em todo caso, ele exercerá uma efetuação coletiva produzindo a extensão e a socialização de sua personalidade"' (SARTRE, 1972, p. 188 apud FETSCHER, 1988, p. 243).

doispontos, Curitiba, São Carlos, vol. 3, n. 2, p.173-188, outubro, 2006. 
${ }^{1}$ Em ADORNO, 1962, Adorno reprova a Sartre o seu "subjetivismo extremo".

\section{Referências bibliográficas}

ADORNO, T.W. 1962. "Dialektik und Engagement". Die neue Rundschau. $\mathrm{n}^{\circ} 1-3$. 1966. Negative Dialektik. Frankfurt: Suhrkamp.

FETSCHER, I. 1988. Sartre und der Marxismus. KÖNIG, T. Sartre. Ein Kongress. Rowohlt, Reinbek b. Hamburg.

FLYNN, T. 1985. Sartre's Marxist Existentialism. Chicago: Chicago University Press.

FRETZ, L. 1988. Knappheit und Gewalt: Kritik der dialektischen Vernunft. KÖNIG, T. Sartre. Ein Kongress. Rowohlt, Reinbek b. Hamburg.

MOUILLIE, J.-M. 2000. Sartre et la phénoménologie. Fontenay-auxRoses: ENS éditions.

NOUDELMANN, F. e PHILIPPE, G. 2004. Dictionnaire Sartre. Paris: Honoré Champion.

RIZK, H. 1996. La constitution de l'Etre social (Le statut ontologique du Collectif dans la Critique de la raison dialectique). Paris: Kimé.

SARTRE, J.-P. 1943. L'être et le néant. Paris: Gallimard. 1960. Critique de la raison dialectique. t. I. Paris:

Gallimard. 1972. « Autour de 68 ». Situations VIII. Paris:

Gallimard.

SEEL, G. 1995. La dialectique de Sartre. Lausanne: L'Age d'Homme. ZEHM, G. A. 1964. Historische Vernunft und direkte Aktion (Zur Politik und Philosophie Jean-Paul Sartres). Stuttgart: Klett. 